Article

\title{
Can Citizens Affect the Performance of Their Elected Representatives? A Principal-Agent Model of Strategic Interaction in Democratic Systems
}

\author{
Giuseppe Lanza*(D), Dario Maimone Ansaldo Patti and Pietro Navarra \\ Department of Economics, University of Messina, Piazza Pugliatti 1, 98122 Messina, Italy; \\ dmaimone@unime.it (D.M.A.P.); navarrap@unime.it (P.N.) \\ * Correspondence: glanza@unime.it; Tel.: +39-090-6766164
}

Received: 15 May 2020; Accepted: 17 July 2020; Published: 21 July 2020

\begin{abstract}
According to standard economic theory, human beings are expected to work more and better when benefits in the form of lower costs or higher reward increase. Principal-agent theory applied to the theory of the firm relies on this relationship and states that employees should be paid according to how well they perform their tasks. In this framework, monitoring devices are introduced to control employees' performance and determine salaries. In this paper we construct a principal-agent model to describe the relationship between citizens/voters and elected representatives in which monitoring devices are introduced to control the performance of the latter. We demonstrate that tighter controls may produce better performance but also may produce a reduction in the intrinsic motivations of elected representatives, resulting in a reduction of their work effort. These results are interpreted in the light of the motivation crowding theory.
\end{abstract}

Keywords: principal-agent theory; monitoring; intrinsic motivation; crowding out

\section{Introduction}

Representative democracies are characterized by a peculiar relationship between politicians and citizens/voters. The latter receive a mandate from the former to govern on their behalf. Such a relationship evolves as a principal-agent one, where citizens/voters are principals and politicians are their agents. The agency contract should guarantee, as much as possible, that the agents conform to their contractual obligations. Hence, the structure of the contract should perform an alignment in the interests of agents and principals. It follows that the more effective the design of the democratic contract is, the better the elected representatives (agents) will act in the interest of the citizens (principals). Consequently, any change in the features of the contract is supposed to affect the relationship between citizens and politicians and, therefore, their performance in pursuing collective interests.

Can citizens/voters change the structure of the democratic contract to improve the performance of their representatives? A large base of literature in political economics argues that the democratic relationship between voters and elected representatives can be affected by a change in the legislative and/or electoral institutions. These changes affect political accountability of elected representatives and in turn the ability of politicians to act in the interests of the voters [1-6].

A different way to enhance the performance of elected representatives is to implement new and/or more effective monitoring devices to control the actions of elected representatives. An example of how voters can directly monitor the actions of elected representatives consists of changing the electoral system. Italy, Japan and New Zealand, amongst several other democratic countries, have altered their election rules in the past decades to improve the accountability of elected representatives $[7,8]$. The former communist countries in Eastern Europe introduced elections to directly reward (punish) 
elected governments that acted (did not act) in the interest of voters, although this is clearly not the only reason explaining the democratization of Eastern European countries after the collapse of communism [9]. However, if citizens/voters can directly monitor the actions of elected representatives through a variation in the rules governing the system of representation, they can also exercise an indirect control through the judicial system $[10,11]$. Again, large judicial operations to uncover widespread corruption in the public sector, such as those that exploded in Italy, Germany and Spain, are all examples of indirect monitoring of politicians' activities. In this paper, we develop a model to evaluate the effects produced by these monitoring devices on the performance of elected representatives.

We construct a principal-agent model describing the relationship between citizens/voters and their elected representatives. In this framework, we analyze whether a change in the control exercised by citizens/voters over the activities undertaken by their representatives in the government affects the performance of the latter. We use the motivation crowding theory to emphasize that governmental behavior of politicians is driven by a combination of intrinsic and extrinsic motivations [12-18]. Further, we demonstrate that monitoring the administrative actions of public officials may foster or impair their performance depending on the extent to which their activities are intrinsically or extrinsically motivated. It should be noted that a possible reduction in the activity of politicians is not an immediate consequence of a punishment that they suffer, but it could primarily be the consequence of a decline in their intrinsic motivations.

As previously mentioned, we attempt to model the interaction between citizens and elected representatives that are under the control of judicial activity. Our concern is about how to make such a relationship more efficient. Of course, judicial activity may not necessarily have a beneficial impact on such a relationship, since, as we noted above, crowding out theory may be in operation. Our idea of modeling such a relationship through the actions of judges stems from the observations of the events that occurred in Italy in the 1990s. Following an apparently marginal episode of corruption in the public sector, a huge investigation scrutinized the activities of politicians at both national and local levels. Such an operation was meant to extirpate corruption in public officials and politicians. However, judges' intervention might not generate only positive effects. In fact, Limosani, Maimone Ansaldo Patti and Navarra [19] show empirically that the activity of politicians at the local level has been crowded out by the judicial operation, since even highly ethically motivated politicians could find the intervention too strong and possibly not worthy to be faced, even though they were not involved in any illegal activity.

The paper is structured as follows. In Section 2, we introduce the related literature. In Section 3, we construct our model. In Section 4, we discuss how citizens/voters can affect the level of performance of their elected representatives, and finally, in Section 5, we present some concluding remarks.

\section{Theoretical Framework}

We construct a model describing the relationship between citizens/voters and elected representatives. In this agency relationship, citizens/voters are the principals and the elected representatives are the agents. The principals use monitoring devices in order to increase the performance of the agents. The performance of elected representatives is measured in terms of policy outcomes. Since elected representatives receive a mandate to pursue the collective interest, the policy outcome we refer to is the one that at best satisfies citizen/voter preferences. Therefore, high-performance elected representatives are those that carry out their electoral mandate pursuing the interests of citizens/voters. By the same token, low-performance elected representatives are those that carry out their electoral mandate pursuing their own interests to the detriment of collective well-being.

In the context of a principal-agent relationship, the effects of both extrinsic and intrinsic motivations on individual performance can be shown [12,20-23]. Standard principal-agent models focus on the fact that the principal's payoff depends on the ability of the agent to perform a task, but, since the agent's preferences differ from those of the principal, there is a conflict of interest and agents will be 
tempted to exploit every opportunity to reduce their effort level [24-26], all this leading to a moral hazard problem $[27,28]$.

Therefore, principals often use monitoring and economic incentive in order to induce agents to perform properly and increase the effort level as expected. While initially, principal-agent theory had focused on the use of monetary incentives in order to pursue the alignment of the agent's self-interest with that of the principal (reward the wanted behavior), later this perspective was extended to include regulation and in particular monitoring activities [29-32]. Regulation means that the principal sets up norms, rules and directives, which are eventually sanctioned after monitoring. Unwanted behavior and the lack of wanted behavior are sanctioned instead of being rewarded, but the logic is the same as for rewards [33]. Assuming disutility of effort, with stricter monitoring, standard theory predicts that a self-interested agent will perform harder to decrease the likelihood of a sanction if caught shirking $[23,24,34-36]$.

However, social psychological research has focused on the relationship between intrinsic and extrinsic motivation, demonstrating the relevance of intrinsic motivation for work and performance and that an external intervention, such as economic reward or monitoring, may reduce intrinsic motivation permanently [37-45].

Strictly following Deci's definition, "to be intrinsically motivated means to engage in an activity because the activity itself is interesting and enjoyable" [46] (p. 11), that is, an individual is moved in performing the task by behavioral motives coming from the inner person (inner feelings, morality, enjoyment), rather than because of external monitoring or rewards. Similar definitions can be found in Deci [37] (p. 105), namely that "one is said to be intrinsically motivated to perform an activity when one receives no apparent reward except the activity itself" and in Ryan and Deci [47], where intrinsic motivation is defined "as the doing of an activity for its inherent satisfactions rather than for some separable consequence".

We agree with this definition, however, given that we are describing the behavior of public officials, we are going to consider a wider definition of intrinsic motivation which contain what has been termed in the literature as public service motivation theory [48-51]; reviews of recent literature can be found in [52,53]. According to this theory, working with public service is considered a special calling [49], so that generally, a public employee is also motivated by a desire to perform well and contribute to the well-being of the society, by a wish to work for what they conceive of as public interest [54-56]. Rainey and Steinbauer [57] stress that public service motivation consists of working in such a way to offer an appropriate service to the majority of people, differently from the selfish motivation that they define as a special kind of altruism: "a general, altruistic motivation to serve the interests of a community of people". According to the literature, initially developed by Perry [54], this type of intrinsic motivation depends on four dimensions: "commitment to the public interest", which is characterized by the desire to serve society based on values and duty; "compassion", which emphasizes the emotionally-based motivation to perform efficiently in favor of people on the basis of identification and empathy; "attraction to policy-making", which refers to the motivation of improving decision-making concerning public services; and "self-sacrifice", which measures the intention to go beyond one's own needs in order to help persons in the society $[54,58]$.

In our opinion, elected public officials that are highly motivated with respect to these four dimensions are, with high probability, those who are highly productive and truly carry out their electoral mandate pursuing the interests of citizens/voters. As a result of our reasoning, when we discuss the intrinsic motivation of the elected representatives, we will extensively intend to refer not only to the enjoyment and interest in their task but also to the concept of public service motivation as discussed above.

By contrast, extrinsic motivation represents incentives coming from the outside, i.e., it is a concept that applies whenever an activity is done in order to attain some separable outcome. External intervention, like monetary incentives or monitoring, may compromise intrinsic motivation (crowding out) and decrease performance (the hidden cost of reward). In particular, interventions like monitoring, 
control and supervision are supposed to produce a significant and systematic impact on the effect of intrinsic motivations on preferences about effort level.

Frey [13-16,59] introduces this crowding theory to economics and discusses possible motivational consequences arising from pricing and regulation with respect to constitutional design, crime prevention, environmental policy, blood donation and tax policy, arguing that the impact of external interventions on intrinsic motivation depends on how such interventions are perceived, especially if the agents display a large initial level of intrinsic motivation. He also focuses on work morale and on how regulations and monitoring may affect shirking incentives $[14,60]$. Agents may judge the adoption of devices such as monitoring and contingent rewards as evidence of distrust, and this can lead to a reduction of work effort and performance; furthermore, this kind of external intervention can deteriorate work morale, making agents less efficient as a means of influencing behavior. Such relationships are assumed to be critically important for nonrepetitive jobs or tasks where factors like high discretion, intuition, creativity, commitment and self-sacrifice play a crucial role in the accomplishment of the job. In our opinion, good examples could be high-level and elected public officials.

Crowding theory, therefore, is a critical problem that agency theory analyzes, since it questions the possibility of control of agents by external intervention. When a principal introduces extrinsic motivation factors like monitoring, Frey separates the disciplining effect from the crowding effect [17,61]. The disciplining effect of monitoring alters the costs of shirking, while the crowding effect follows monitoring and affects intrinsic motivation: crowding out happens when the external intervention compromises the intrinsic motivation, while crowding in happens when the external intervention increases intrinsic motivation.

Extrinsic motivation factors are a significant part of public sector management, but even though it is hard to think of a public official working just for the enjoyment of the job itself, intrinsic motivations for performing a task surely exist [62] and are also important for the work effort and for the level of performance as well, especially if we refer to the extended concept of intrinsic motivation discussed above which goes well beyond the scope of this work.

Most studies of motivation crowding have concentrated on rewards and particularly on monetary incentives [17,63-65]. These studies support the claim that payments that are evaluated as controlling reduce intrinsic motivation and performance, while payments judged as supportive have the polar effect. Several studies, mostly experimental, have tested the motivation crowding proposition for regulation and monitoring [45,66-69], validating the hypothesis that control, as well as reward, may cause a hidden cost to the principal. Monitoring surely has a positive direct effect in reducing shirking activities; however, there may be an indirect effect on those agents who are highly intrinsically motivated and may can possibly react to control by reducing effort, which can result in an overall negative effect. In other words, some individuals will exhibit a higher effort level if not monitored and a minimum level, just enough to avoid negative consequences, if monitored (for more studies on the detrimental effect of increased monitoring on employees' performance, see also [60,70-73]; these studies all suggest that close monitoring reduces performance, especially when perceived as a signal of distrust).

In the field of monitoring-effort relationship, Frey [60] integrates crowding theory into a standard principal-agent model and provides a theoretical framework to evaluate how a change in the monitoring level may affect agents' intrinsic motivation and so their optimal choice of effort.

In what follows, we reinterpret and adapt Frey's approach to the agency relationship between citizens/voters and elected representatives. The interesting result we obtain is that the effect of stricter monitoring activity on the level of performance depends not only on how agents perceive it, i.e., supportive or controlling (agent type), but also on the type of interaction and on the beliefs that elected representatives formulate about the behavior of citizens. 


\section{A Motivation Theory of Public Officials}

Following Frey's approach, we construct a simple model which allows us to identify the price effect and the crowding effect of stricter monitoring activity. We assume that citizens/voters and elected representatives ( $C V$ and $E R$ from now on) play a sequential-move game in which the latter choose the level of performance, $p$, while citizens select the level of control, $m$, to be exercised over the administrative activities undertaken by public officials. Therefore, $p$ is the only choice variable for the $E R$, and $m$ is the only choice variable for the $C V$. Each player's choice is strategic in the sense that each player moves sequentially on the basis of his/her beliefs on the other player's reaction. In other words, the level of control chosen by $C V$ is conditional to the beliefs that they have about the effects of their choice on the performance of $E R$. The same applies for the $E R$, i.e., the level of performance that they choose is conditional to their beliefs about the effects of their choice on the control exercised by $C V$.

We imagine dynamic interactions over time where $m_{0}$ and $p_{0}$ are the level of monitoring and the level of performance, respectively, which represent the stationary point of the strategies for the past. At some point in time, an external shock intervenes (like political scandal, economic crisis or widespread outbreak) causing either a change in citizens' preference in relation to the performance of politicians or a decrease in the politicians' performance itself. We assume that $C V$ move first and so they consider changing their strategy by implementing a stricter level of control trying to induce politicians to put more effort into the activity they undertake in order to match the new required level of performance or to restore the previous standard equilibrium level. In what follows, we are merely interested in investigating how citizens can positively or negatively affect the performance of their elected representatives through changes in the monitoring level; therefore, the study of possible new equilibria and their stability goes beyond our purpose. As the reader will see, the success of the citizens in affecting the performance of the elected representative in a positive way crucially depends on the correctness of their beliefs about the reaction function of the elected representatives.

In what follows, we first describe the behavior of the $E R$. We derive their actual reaction function, which is the optimal level of performance $p^{*}$ as a function of the level of control $m$ implemented by the citizens. Its slope allows us to identify the type of $E R$ : crowdible-in or crowdible-out. After that, we move backwards, describing the behavior of $C V$. We assume that citizens are rational in the sense that they choose $m$ in order to maximize their utility conditional to the beliefs they form about how politicians respond to a change in the level of monitoring. Hence, citizens have the first-move advantage, and they try to make use of it by looking ahead and working backwards, assuming sequential rationality of $E R$. On the other hand, choosing first may become a disadvantage for the $\mathrm{CV}$ in a context of incomplete information like this when beliefs turn out to be incorrect. We will find out that, as a result of the interaction with incorrect beliefs, citizens exerting tighter control might fail to positively affect performance of the elected representative, ending up with a poorer payoff in utility terms.

\subsection{The Behavior of the Elected Representatives}

$E R$ perform by considering benefits $\left(B^{E R}\right)$ and costs $\left(C^{E R}\right)$ of their actions. Both benefits and costs increase in performance $(p)$. Higher performance has decreasing marginal returns and is associated with increasing marginal costs. In our formulation, however, only benefits are influenced by the external monitoring $(m)$, since the effects associated with a higher level of monitoring are included in the benefit function as an externality term. We also assume that $E R$ form some kind of naive expectations about the monitoring level, i.e., they choose the level of performance assuming a future expected level of monitoring being set equal to the past observation.

The benefits and costs functions of the elected representatives can therefore be written as follows:

$$
\begin{gathered}
B^{E R}=B^{E R}(p, m) ; B_{p}^{E R}>0, B_{p p}^{E R}<0 \\
C^{E R}=C^{E R}(p) ; C_{p}^{E R}>0, C_{p p}^{E R}>0
\end{gathered}
$$


where subscripts indicate partial derivatives. Thus, the utility of the $E R$ can be written as a function of the net benefits:

$$
U^{E R}(p, m)=B^{E R}(p, m)-C^{E R}(p)
$$

Rational ER would like to choose the level of performance $p^{*}$ that maximizes utility, taking the extent of monitoring $m$ to be held constant, so that

$$
B_{p}^{E R}(p, m)=C_{p}^{E R}(p)
$$

The interpretation of Equation (4) is very intuitive: ER choose the level of performance that maximizes their objective function according to the intensity of the control exercised by $C V$. In other words, Equation (4) implicitly defines the reaction function of the ER, i.e., the optimal level of $p$, in term of the level of control, $m$ :

$$
p^{*}=p^{*}(m)
$$

Equation (4) allows us to analyze the effect of variations in the level of control on the behavior of the ER too. Implicitly differentiating (4) with respect to $m$ and solving for $\mathrm{d} p^{*} / \mathrm{d} m$ we obtain

$$
\frac{\mathrm{d} p^{*}}{\mathrm{~d} m}=\frac{B_{p m}^{E R}(p, m)}{C_{p p}^{E R}(p)-B_{p p}^{E R}(p, m)}
$$

Given that the denominator is surely positive, the sign of Equation (6) crucially depends on the characteristics of the benefit function and in particular on the sign of the cross partial derivative $B_{p m}^{E R}(p, m)$. Two possible situations may arise according to the sign of the cross derivative of the benefit function depending on whether an increase in the choice of monitoring level by citizens/voters increases or decreases the marginal benefit of performance for the elected representatives. In other words, the two possible cases depend on whether the function $B^{E R}(p, m)$ is supermodular or submodular in its arguments. Following the terminology given in Bulow et al. [74], performance and monitoring are strategic complementarity and strategic substitute, respectively. We use those two cases to define the ER type:

I $\quad \mathrm{d} p^{*} / \mathrm{d} m>0$ iff $B_{p m}^{E R}>0$ : In this case, we expect the price effect to dominate the substitution effect. A higher level of monitoring of the activities undertaken by the ER should unequivocally raise performance. This result is consistent with traditional agency theory whereby monitoring devices increase effort and performance by imposing higher marginal costs of shirking or, equivalently, by lowering the marginal costs of performing [28,35]. This effect can be also seen as a disciplining effect that higher controls impose on the behavior of the agent. Here, the crowding-out effect does not operate, since monitoring does not affect the marginal benefit of performing as intrinsic motivations are considered constant or nonexistent.

II $\mathrm{d} p^{*} / \mathrm{d} m<0$ iff $B_{p m}^{E R}<0$ : This is the "crowdable-out" case, in which the substitution effect should dominate the price effect. Therefore, higher levels of monitoring activities should crowd out the intrinsic motivations of $E R$ and reduce their performance [13-15]. ER perceive the increase in control as a sign of voters' distrust and lose goodwill in performing their tasks. Both self-motivation and self-esteem suffer, and $E R$ react by lowering their intrinsic motivations to those activities exposed to higher controls. To be precise, a third neglectable case may arise in which the substitution effect and the price effect compensate for each other so that there is not a reaction by $E R$ to any variation in the level of control: $\mathrm{d} p^{*} / \mathrm{d} m=0$ iff $B_{p m}^{E R}=0$.

\subsection{The Behavior of Citizens/Voters}

We now move on to consider the agency relationship from the perspective of $C V$. Briefly, let us start by defining benefits and costs functions. We assume that citizens' benefits positively depend on the level of performance implemented by the ER with decreasing marginal returns. On the other hand, 
costs depend only on the level of external monitoring. Higher levels of monitoring become costly and are associated with increasing marginal costs. We can therefore write the two functions as follows:

$$
\begin{gathered}
B^{C V}=B^{C V}(p) ; B_{p}^{C V}>0, B_{p p}^{C V}<0 \\
C^{C V}=C^{C V}(m) ; C_{m}^{C V}>0, C_{m m}^{C V}>0
\end{gathered}
$$

so that the utility of $C V$ can be written as a function of the net benefits:

$$
U^{C V}(m, p)=B^{C V}(p)-C^{C V}(m)
$$

To gain a better understanding about preferences of $C V$ between monitoring and performance, it can be helpful to analyze the level curves of the utility function by means of the typical indifference curve analysis. Let us first note that the marginal rate of substitution between $m$ and $p$ is

$$
\operatorname{MRS}(m, p)=\left.\frac{\mathrm{d} p}{\mathrm{~d} m}\right|_{U^{C V}=\bar{U}}=\frac{C_{m}^{C V}}{B_{p}^{C V}}
$$

As expected, $\mathrm{CV}$ are willing to accept higher levels of monitoring only if they are associated with higher levels of performance. Furthermore, assumptions in (7) and (8) imply quasi-concavity of the utility function and therefore convex upper contour sets. Graphically, setting $m$ on the horizontal axis, as $m$ increases, the indifference curves will be upward sloping and convex (increasing marginal rate of substitution. In fact, noticing that $\frac{\mathrm{d} M R S}{\mathrm{~d} m}=\frac{C_{m m}^{C V} B_{p}^{C V}-C_{m}^{C V} B_{p p}^{C V} \frac{\mathrm{d} p}{\mathrm{~d} m}}{\left(B_{p}^{C V}\right)^{2}}=\frac{C_{m m}^{C V}\left(B_{p}^{C V}\right)^{2}-B_{p p}^{C V}\left(C_{m}^{C V}\right)^{2}}{\left(B_{p}^{C V}\right)^{3}}$, the assumptions in (7) and (8) imply that $\frac{\mathrm{d} M R S}{\mathrm{~d} m}>0$.

We assume that $C V$ seek to maximize their net benefits using the information they have about how ER react to their intervention. According to Equations (5), (7), (8) and (9), in the case of complete information, citizens would face the following maximization problem:

$$
\max _{m} U^{C V}\left(m, p^{*}(m)\right)=\max _{m}\left[B^{C V}\left(p^{*}(m)\right)-C^{C V}(m)\right]
$$

which would yield the following optimality condition:

$$
B_{p}^{C V}\left(p^{*}\right) \frac{\mathrm{d} p^{*}}{\mathrm{~d} m}=C_{m}^{C V}(m)
$$

Substituting (6) into the above optimality condition we can rearrange it as follows:

$$
\frac{B_{p m}^{E R}(p, m)}{C_{p p}^{E R}(p)-B_{p p}^{E R}(p, m)}=\frac{C_{m}^{C V}(m)}{B_{p}^{C V}\left(p^{*}\right)}
$$

The right-hand side of this expression is the slope of the indifference curve, i.e., the marginal rate of substitution, the rate at which $C V$ are willing to substitute monitoring with performance, keeping utility level constant. The left-hand side is the slope of the $E R$ reaction function: the rate at which the choice of $m$ truly affects $p$ through the behavior of the ER. In Figure 1, we represent the two possible equilibria with complete information. In panel (a), we describe the "crowdable-in" type agent, for which $B_{p m}^{E R}>0$. In this scenario, maximizing utility for the $C V$ implies choosing a level of monitoring so that a citizens' indifference curve is tangent to the $E R$ reaction function. In panel (b), we represent the "crowdable-out" case in which $B_{p m}^{E R}<0$. In such a case, the optimality condition in (13) can never be fulfilled, and a boundary solution solves the problem in (11) so that the optimal level of monitoring is equal to the lowest feasible level, say $\underline{m}$. 


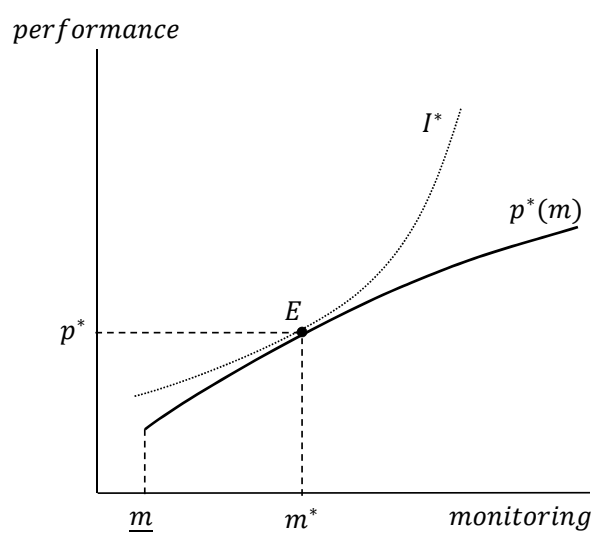

(a)

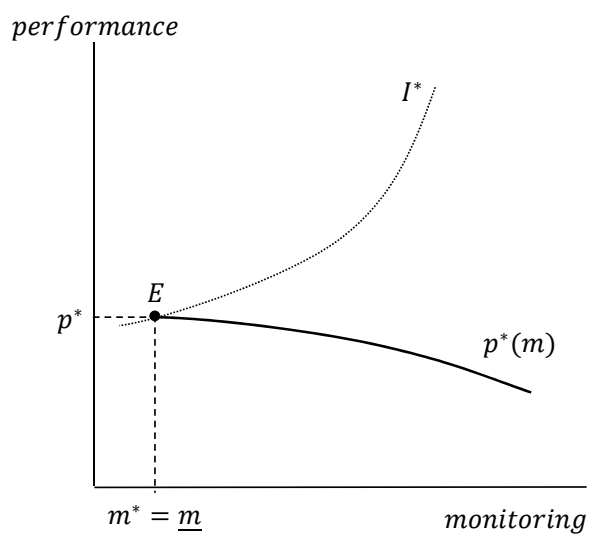

(b)

Figure 1. (a) "Crowdable-in" case; (b) "crowdable-out" case.

\section{How Citizens Can Affect the Performance of Their Elected Representatives}

When the negative exogenous shock takes place, there is a variation in the preferences of the $C V$ (shifts and/or rotations of the indifference curves). As a consequence of these changes, the previous level of performance $p_{0}$ is now perceived as unsatisfactory, and therefore $C V$ will ponder exerting a different level of monitoring in order to affect the level of performance of the $E R$. How should they use control to induce the desired change in the level of performance implemented by the politicians?

In order to answer this question, notice that we have already found the actual function describing the reaction of $E R$ to changes in the level of monitoring in Equation (5). However, because of lack of information, it is plausible to assume that $C V$ form beliefs about this reaction and then make the optimal decision on the level of monitoring on the basis of these beliefs. In other words-as already pointed out-we assume that $C V$ are rational in the sense that they choose the level of monitoring which maximizes their perceived payoffs. In such a scenario, let us indicate with $\widetilde{p}$ the believed (by $C V$ ) reaction function of the $E R$ and with $\widetilde{a}(m)=d \widetilde{p} / d m$ the beliefs of $C V$ about the reaction of the $E R$ to a change in the level of monitoring. Therefore, the actual pondered f.o.c. is

$$
B_{p}^{C V}(\widetilde{p}) \widetilde{a}(m)=C_{m}^{C V}(m)
$$

which, in turn, yields the optimal level of subjective monitoring, $\widetilde{m}^{*}$.

Note that the slope of the believed reaction function of the citizens, $\widetilde{a}(m)$, can be interpreted in the same vein of a conjectural variation and, in general, could be any kind of function depending on $m$. For the sake of simplicity, let us design a linear belief model assuming it to be a constant, i.e., $\widetilde{a}(m)=\widetilde{a}$. Hence, the believed reaction function of $C V$ takes the following simple form:

$$
\widetilde{p}(m)=p_{0}+\widetilde{a}\left(m-m_{0}\right)
$$

In words, $C V$ assume that $E R$ will observe the variation in the level of monitoring from past level $m_{0}$ and they will react by changing their performance with respect to the starting level $p_{0}$ by a quantity proportional to the initial deviation $m-m_{0}$. Now, substituting (15) into (14) and solving with respect to $m$ allows us to obtain the subjective optimal level of monitoring which depends, of course, on the belief $\widetilde{a}$ and on the initial values $p_{0}$ and $m_{0}$ :

$$
\widetilde{m}^{*}=\widetilde{m}^{*}\left(\widetilde{a}, p_{0}, m_{0}\right)
$$


At this point, $E R$ observe the level of monitoring $\widetilde{m}^{*}$ and then rationally decide their level of performance. In other words, we need to substitute (16) into (5) to obtain the new level of performance as the result of the interaction between citizens and their $E R$ :

$$
p^{*}\left(\widetilde{m}^{*}\right)=p^{*}\left[\widetilde{m}^{*}\left(\widetilde{a}, p_{0}, m_{0}\right)\right]
$$

It should be clear at this point that if $C V$ believe that $E R$ are "crowdable-in" types and so react positively to more external controls $(\widetilde{a}>0)$, they should exert tighter monitoring to induce higher performance. In other words, in this case, $C V$ believe that a higher level of monitoring is effective and so they use it $\left(\widetilde{m}^{*}>m_{0}\right)$. On the other hand, if $C V$ believe that monitoring undermines intrinsic motivation up to a point at which the crowding-out effect eventually dominates the price effect, i.e., when $\widetilde{a} \leq 0$, they should abstain or reduce their monitoring activities. In this case, the level of monitoring should be decreased and set to the minimal possible level $\underline{m}$ (i.e., $\widetilde{m}^{*}=\underline{m}<m_{0}$ ). In other words, if this is the case, $C V$ believe that $E R$ are intrinsically motivated and deem that a signal of trust, via the reduction in monitoring activities, would foster their self-determination and this would raise their performance.

Now, let us define beliefs to be correct when they are directionally right, i.e., when $\operatorname{sign}(\widetilde{a})=$ $\operatorname{sign}\left(\mathrm{d} p^{*} / \mathrm{d} m\right)$. Beliefs that are "precise", not just on the "direction", are said to be "precisely right", i.e., $\widetilde{a}=\mathrm{d} p^{*} / \mathrm{d} m$. For our purpose, we prefer to keep our reasoning as general as possible, considering beliefs to be correct when the direction of the supposed monitoring effect is correct. Notice that, according to this definition, beliefs might be correct but yet precisely wrong: $\operatorname{sign}(\widetilde{a})=\operatorname{sign}\left(\mathrm{d} p^{*} / \mathrm{d} m\right)$ but $\widetilde{a} \neq \mathrm{d} p^{*} / \mathrm{d} m$.

In Figure 2a, we represent a possible scenario in which ER actually react positively to more control $\left(\mathrm{d} p^{*} / \mathrm{d} m>0\right)$ and $C V$ form correct beliefs (even though they overestimate the reaction of $E R$, they are directionally right). The point $E_{0}$ represents the past equilibrium, while the perceived new optimum level of monitoring $\widetilde{m}^{*}$ is in point $\widetilde{E}_{1}$ of tangency between the indifference curve $\widetilde{I}_{1}$ and the believed reaction curve of the $E R, \widetilde{p}(m)$. In this case, $C V$ increase monitoring from $m_{0}$ to $\widetilde{m}^{*}$, at the end causing an increase in the level of performance from $p_{0}$ to $p^{*}\left(\widetilde{m}^{*}\right)$. In this case, correct beliefs lead to a higher level of performance and to a utility improvement for $C V$. However, since beliefs are precisely wrong, $\mathrm{CV}$ actually improve their utility level less than expected. The same reasoning applies for the case of $E R$ actually reacting negatively to more control $\left(\mathrm{d} p^{*} / \mathrm{d} m<0\right)$ and $C V$ forming correct beliefs $(\widetilde{a}<0)$.

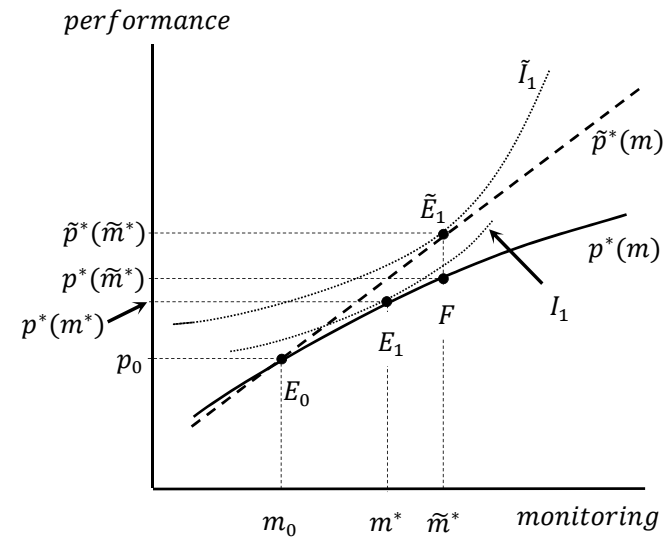

(a)

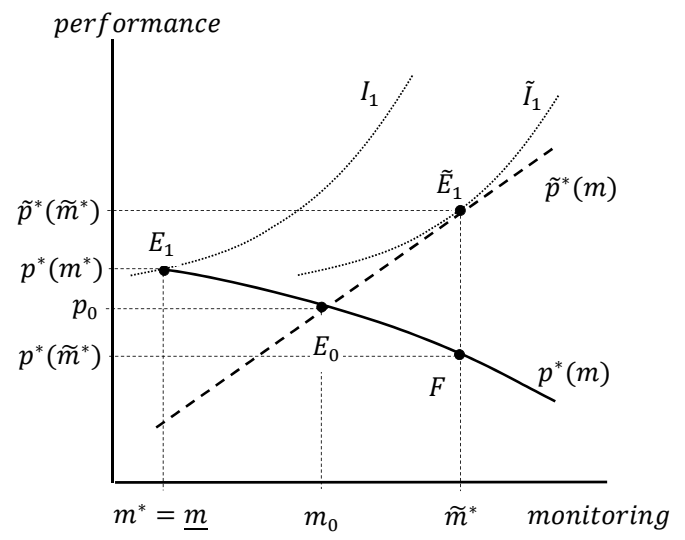

(b)

Figure 2. (a) Correct beliefs case; (b) incorrect beliefs case. 
In Figure $2 b$, we show a possible case of $C V$ forming incorrect beliefs. In this case, $C V$ erroneously believe that $E R$ respond positively to more control, therefore thinking to behave optimally by increasing the level of control from $m_{0}$ to $\widetilde{m}^{*}$, with this causing a decrease in the level of performance from $p_{0}$ to $p^{*}\left(\widetilde{m}^{*}\right)$. As a consequence of the incorrect beliefs, the crowding-out effect takes place instead of the expected reaction. In other words, ER feel like their involvement and effort are not appreciated by $C V$. In this context, a higher level of monitoring can be seen as an indication of distrust or as a unilateral breach of the democratic contract between $C V$ and $E R$ built on a mutual trust: the self-determination of $E R$ will be depressed and the perception of voters' distrust would crowd-out work performance $[13,14,75]$. In this scenario, $C V$ think to improve their utility level by moving from the indifference curve passing through the point $E_{0}$, for instance $I_{0}$, to $\widetilde{I}_{1}$, while, instead, they end up with a lower level of utility, say $I_{2}$, represented by the indifference curve passing through the point $F$ (not shown in the figure). The same reasoning applies for the case of $E R$ actually reacting positively to more control $\left(\mathrm{d} p^{*} / \mathrm{d} m>0\right)$, while $C V$, who trust their $E R$, have incorrect beliefs $(\widetilde{a}<0)$ in thinking that they are intrinsically motivated and so decrease control activities.

As a result of our reasoning, it is clear that $C V$ can positively affect the performance of their $E R$ only if they form correct beliefs about their reaction to a change in the level of monitoring.

\section{Conclusions}

Despite the fact that the literature relating to human motivation spans many research areas such as anthropology, psychology and sociology, economists by and large have long maintained their own opinion about individual motivation without cross-references with other disciplines. The economic point of view rests on the fact that human behavior is motivated by external incentives in the form of monetary rewards and/or sanctions [76,77]. However, there has recently been a surge of interest in a more interdisciplinary approach to explain human motivation. Following the steps indicated by researchers in human resource management [38], economists have started to believe that individuals' actions are no longer determined only by 'carrots and sticks', but rather by a combination of intrinsic and extrinsic motivations [13,14].

This approach has been used to explain human behavior in various social and economic contexts [17], but little attention has been devoted to explaining human motivations within the democratic relationship between citizens/voters and elected representatives. In this paper, we have tried to fill this gap. We have formulated a model describing the relationship between voters and elected representatives in a principal/agent setting. The former are viewed as principals and the latter as agents. In this framework, we analyzed whether citizens/voters may increase the performance of public officials through institutional changes that alter the control that they exercise over the actions undertaken by the agents.

In our model, we challenge the belief that more stringent monitoring leads to higher government performance. According to Frey, we argue that elected representatives may act on the basis of only intrinsic or extrinsic motivations, or on the basis of a combination of the two. Our argument stems from the hypothesis that the agency relationship between voters and elected representatives consists in an implicit psychological contract, as the latter receive the electoral mandate from the former. Contrary to the traditional agency theory [26] and in line with the crowding hypothesis $[15,16]$, we demonstrate that there might be cases in which an increase in control exercised by citizens/voters breaches this implicit democratic contract. This occurs because citizens/voters, by increasing monitoring activities, signal distrust toward the politicians' willingness to perform their tasks. As a consequence, elected representatives will be inclined to reduce their work effort. Therefore, there might be the possibility in which monitoring the activities of elected representatives may result in the undesired outcome of reducing the government performance of elected representatives.

Clearly, our model is only an attempt to characterize the relationship between citizens and elected representatives and to depict their democratic contract. While we used a principal-agent model to explain such a relationship, we tried to keep it as simple as possible. In fact, future research can 
take into consideration some elements that are not included in this paper. For instance, we did not explicitly model agency costs (or at least we posed them equal to 0). Obviously, it would be interesting to check whether our model could change if agency costs are brought in. Additionally, a future development of the model could also further stress the asymmetric information that usually characterizes a principal-agent model. Such an aspect is not fully developed in the present research, but it would be interesting to move to an incomplete information set-up to appreciate again the evolution of our model.

Author Contributions: This work is the outcome of joint efforts of G.L., D.M.A.P. and P.N., who contributed equally to conceive, elaborate and design the research. All authors have read and approved the final the version of the manuscript.

Funding: This research received no external funding.

Acknowledgments: We would like to thank Valentino Dardanoni, Ram Mudambi, Abhinay Muthoo, Gulcin Ozkan, Damiano Silipo and Giuseppe Sobbrio for helpful suggestions throughout the preparation of this work. The usual disclaimer applies.

Conflicts of Interest: The authors declare no conflict of interest.

\section{References}

1. Cox, G.W. Making Votes Count: Strategic Coordination in the World's Electoral Systems; Political Economy of Institutions and Decisions; Cambridge University Press: Cambridge, UK; New York, NY, USA, 1997; ISBN 978-0-521-58516-3.

2. Drazen, A. Political Economy in Macroeconomics; Princeton University Press: Princeton, NJ, USA, 2002; ISBN 978-0-691-09257-7.

3. Myerson, R.B. Economic Analysis of Constitutions. Univ. Chic. Law Rev. 2000, 67, 925-940. [CrossRef]

4. Persson, T.; Tabellini, G.E. Political Economics: Explaining Economic Policy; Zeuthen Lecture Book Series; MIT Press: Cambridge, MA, USA, 2000; ISBN 978-0-262-16195-4.

5. Persson, T.; Tabellini, G.; Trebbi, F. Electoral Rules and Corruption. J. Eur. Econ. Assoc. 2003, 1, $958-989$. [CrossRef]

6. Tsebelis, G. Veto Players: How Political Institutions Work; Princeton University Press: Princeton, NJ, USA, 2002; ISBN 978-0-691-09988-0.

7. Mudambi, R.; Navarra, P.; Sobbrio, G. (Eds.) Rules, Choice and Strategy: The Political Economy of Italian Electoral Reform; The Locke Institute Series; Edward Elgar: Cheltenham, UK; Northampton, MA, USA, 2001; ISBN 978-1-84064-600-9.

8. Shugart, M.S.; Wattenberg, M.P. (Eds.) Mixed-Member Electoral Systems: The Best of Both Worlds? Comparative European politics; Oxford University Press: Oxford, UK; New York, NY, USA, 2001; ISBN 978-0-19-924079-1.

9. Huntington, S.P. The Third Wave: Democratization in the Late Twentieth Century; The Julian J. Rothbaum Distinguished Lecture Series; Paperback Print; University of Oklahoma Press: Norman, OK, USA, 1993; ISBN 978-0-8061-2516-9.

10. Myerson, R.B. Effectiveness of Electoral Systems for Reducing Government Corruption: A Game-Theoretic Analysis. Games Econ. Behav. 1993, 5, 118-132. [CrossRef]

11. Bicchieri, C.; Mudambi, R.; Navarra, P. A matter of trust: The search for accountability in Italian politics, 1990-2000. Mind Soc. 2005, 4, 129-148. [CrossRef]

12. Bénabou, R.; Tirole, J. Intrinsic and Extrinsic Motivation. Rev. Econ. Stud. 2003, 70, 489-520. [CrossRef]

13. Frey, B.S. Motivation as a limit to pricing. J. Econ. Psychol. 1993, 14, 635-664. [CrossRef]

14. Frey, B.S. Shirking or work morale?: The impact of regulating. Eur. Econ. Rev. 1993, 37, 1523-1532. [CrossRef]

15. Frey, B.S. A Constitution for Knaves Crowds Out Civic Virtues. Econ. J. 1997, 107, 1043-1053. [CrossRef]

16. Frey, B.S. Not Just for the Money: An Economic Theory of Personal Motivation; Edward Elgar Pub: Cheltenham, UK; Brookfield, VT, USA, 1997; ISBN 978-1-85898-509-1.

17. Frey, B.S.; Jegen, R. Motivation Crowding Theory. J. Econ. Surv. 2001, 15, 589-611. [CrossRef]

18. Weibel, A.; Wiemann, M.; Osterloh, M. A Behavioral Economics Perspective on the Overjustification Effect. In The Oxford Handbook of Work Engagement, Motivation, and Self-Determination Theory; Gagné, M., Ed.; Oxford University Press: New York, NY, USA, 2014; ISBN 978-0-19-979491-1. 
19. Limosani, M.; Maimone Ansaldo Patti, D.; Navarra, P. Il Rapporto di Agenzia tra Elettori ed Eletti e gli Effetti di Mani Pulite sulle Decisioni di Politica Economica Locale. Econ. Pubblica 2003, 5, 61-74.

20. Bolle, F.; Otto, P.E. A Price Is a Signal: On Intrinsic Motivation, Crowding-out, and Crowding-in. Kyklos 2010, 63, 9-22. [CrossRef]

21. Gibbons, R. Incentives in Organizations. J. Econ. Perspect. 1998, 12, 115-132. [CrossRef]

22. Miller, G.J. The political evolution of principal-agent models. Annu. Rev. Polit. Sci. 2005, 8, $203-225$. [CrossRef]

23. Prendergast, C. The Provision of Incentives in Firms. J. Econ. Lit. 1999, 37, 7-63. [CrossRef]

24. Alchian, A.A.; Demsetz, H. Production, Information Costs, and Economic Organization. Am. Econ. Rev. 1972, 62, 777-795.

25. Douma, S.W.; Schreuder, H. Economic Approaches to Organizations, 6th ed.; Pearson: Harlow, UK; New York, NY, USA, 2017; ISBN 978-1-292-12890-0.

26. Sappington, D.E.M. Incentives in Principal-Agent Relationships. J. Econ. Perspect. 1991, 5, 45-66. [CrossRef]

27. Holmstrom, B. Moral Hazard and Observability. Bell J. Econ. 1979, 10, 74. [CrossRef]

28. Hart, O.; Holmström, B. The theory of contracts. In Advances in Economic Theory; Bewley, T.F., Ed.; Cambridge University Press: Cambridge, UK, 1987; pp. 71-156. ISBN 978-0-521-38925-9.

29. Mitnick, B. The Strategic Uses of Regulation-And Deregulation. In Corporate Political Agency: The Construction of Competition in Public Affairs; SAGE Publications, Inc.: Thousand Oaks, CA, USA, 1993; pp. 68-89. ISBN 978-0-8039-4349-0.

30. Mitnick, B.M. Regulation and the theory of agency. Rev. Policy Res. 1982, 1, 442-453. [CrossRef]

31. Weingast, B.R. The congressional-bureaucratic system: A principal agent perspective (with applications to the SEC). Public Choice 1984, 44, 147-191. [CrossRef]

32. Dye, R.A. Optimal Monitoring Policies in Agencies. RAND J. Econ. 1986, 17, 339. [CrossRef]

33. Gneezy, U.; Rustichini, A. A Fine is a Price. J. Leg. Stud. 2000, 29, 1-17. [CrossRef]

34. Calvo, G.A.; Wellisz, S. Supervision, Loss of Control, and the Optimum Size of the Firm. J. Polit. Econ. 1978, 86, 943-952. [CrossRef]

35. Fama, E.F.; Jensen, M.C. Separation of Ownership and Control. J. Law Econ. 1983, 26, 301-325. [CrossRef]

36. Laffont, J.-J.; Martimort, D. The Theory of Incentives: The Principal-Agent Model; Princeton University Press: Princeton, NJ, USA, 2002; ISBN 978-0-691-09183-9.

37. Deci, E.L. Effects of externally mediated rewards on intrinsic motivation. J. Pers. Soc. Psychol. 1971, 18, 105-115. [CrossRef]

38. Deci, E.L. Intrinsic Motivation; Springer US: Boston, MA, USA, 1975; ISBN 978-1-4613-4448-3.

39. Deci, E.L.; Ryan, R.M. Intrinsic Motivation and Self-Determination in Human Behavior; Perspectives in Social Psychology; Plenum: New York, NY, USA, 1985; ISBN 978-0-306-42022-1.

40. Deci, E.L.; Koestner, R.; Ryan, R.M. A meta-analytic review of experiments examining the effects of extrinsic rewards on intrinsic motivation. Psychol. Bull. 1999, 125, 627-668. [CrossRef]

41. Festré, A.; Garrouste, P. Theory and evidence in psychology and economics about motivation crowding out: A possible convergence? J. Econ. Surv. 2015, 29, 339-356. [CrossRef]

42. Gneezy, U.; Meier, S.; Rey-Biel, P. When and Why Incentives (Don't) Work to Modify Behavior. J. Econ. Perspect. 2011, 25, 191-210. [CrossRef]

43. Lepper, M.R.; Greene, D. The Hidden Costs of Reward: New Perspectives on the Psychology of Human Motivation; Psychology Press: New York, NY, USA, 2016; ISBN 978-1-317-35675-2.

44. Staw, B.M. Intrinsic and Extrinsic Motivation; University Programs Modular Studies; General Learning Press: Morristown, NJ, USA, 1976; ISBN 978-0-382-25084-2.

45. Weibel, A. Managerial objectives of formal control: High motivation control mechanisms. In Organizational Control; Sitkin, S.B., Cardinal, L.B., Bijlsma-Frankema, K.M., Eds.; Cambridge University Press: Cambridge, UK, 2010; pp. 434-462. ISBN 978-0-511-77789-9.

46. Deci, E.L.; Ryan, R.M.; Vansteenkiste, M. Self-determination theory and the explanatory role of psychological needs in human well-being. In Capabilities and Happiness; Bruni, L., Comim, F., Pugno, M., Eds.; Oxford University Press: Oxford, UK, 2008; pp. 187-223. ISBN 978-0-19-953214-8.

47. Ryan, R.M.; Deci, E.L. Intrinsic and Extrinsic Motivations: Classic Definitions and New Directions. Contemp. Educ. Psychol. 2000, 25, 54-67. [CrossRef] 
48. Bellè, N.; Cantarelli, P. Public service motivation: The state of the art. In Reforming the Public Sector: How to Achieve Better Transparency, Service, and Leadership; Tria, G., Valotti, G., Eds.; Brookings Institution Press: Washington, DC, USA, 2012; ISBN 978-0-8157-2288-5.

49. Perry, J.L.; Hondeghem, A. (Eds.) Motivation in Public Management: The Call of Public Service; Oxford University Press: New York, NY, USA, 2008; ISBN 978-0-19-923403-5.

50. Perry, J.L. Bringing Society In: Toward a Theory of Public-Service Motivation. J. Public Adm. Res. Theory 2000, 10, 471-488. [CrossRef]

51. Wright, B.E. Public-Sector Work Motivation: A Review of the Current Literature and a Revised Conceptual Model. J. Public Adm. Res. Theory 2001, 11, 559-586. [CrossRef]

52. Vandenabeele, W.; Ritz, A.; Neumann, O. Public service motivation: State of the art and conceptual cleanup. In The Palgrave Handbook of Public Administration and Management in Europe; Ongaro, E., Van Thiel, S., Eds.; Palgrave Macmillan UK: London, UK, 2018; ISBN 978-1-137-55268-6.

53. Homberg, F.; Costello, J. Public Service Motivation and Civic Engagement: The Role of Pro-social Motivations in Shaping Society; Palgrave Pivot: Cham, Switzerland, 2019; ISBN 978-3-030-02452-9.

54. Perry, J.L. Measuring Public Service Motivation: An Assessment of Construct Reliability and Validity. J. Public Adm. Res. Theory 1996, 6, 5-22. [CrossRef]

55. Perry, J.L.; Wise, L.R. The Motivational Bases of Public Service. Public Adm. Rev. 1990, 50, 367-373. [CrossRef]

56. Rainey, H.G. Reward Preferences among Public and Private Managers: In Search of the Service Ethic. Am. Rev. Public Adm. 1982, 16, 288-302. [CrossRef]

57. Rainey, H.G.; Steinbauer, P. Galloping Elephants: Developing Elements of a Theory of Effective Government Organizations. J. Public Adm. Res. Theory 1999, 9, 1-32. [CrossRef]

58. Kim, S.; Vandenabeele, W. A Strategy for Building Public Service Motivation Research Internationally. Public Adm. Rev. 2010, 70, 701-709. [CrossRef]

59. Frey, B.S. Tertium Datur: Pricing, Regulating and Intrinsic Motivation. Kyklos 1992, 45, 161-184. [CrossRef]

60. Frey, B.S. Does Monitoring Increase Work Effort? The Rivalry with Trust and Loyalty. Econ. Inq. 1993, 31, 663-670. [CrossRef]

61. Frey, B.S. How Intrinsic Motivation is Crowded out and in. Ration. Soc. 1994, 6, 334-352. [CrossRef]

62. Miller, G.J.; Whitford, A.B. The Principal's Moral Hazard: Constraints on the Use of Incentives in Hierarchy. J. Public Adm. Res. Theory 2007, 17, 213-233. [CrossRef]

63. Andersen, L.B.; Pallesen, T. "Not Just for the Money?" How Financial Incentives Affect the Number of Publications at Danish Research Institutions. Int. Public Manag. J. 2008, 11, 28-47. [CrossRef]

64. Bertelli, A.M. Motivation Crowding and the Federal Civil Servant: Evidence from the U.S. Internal Revenue Service. Int. Public Manag. J. 2006, 9, 3-23. [CrossRef]

65. Gneezy, U.; Rustichini, A. Pay Enough or Don't Pay at All. Q. J. Econ. 2000, 115, 791-810. [CrossRef]

66. Bohnet, I.; Frey, B.S.; Huck, S. More Order with Less Law: On Contract Enforcement, Trust, and Crowding. Am. Polit. Sci. Rev. 2001, 95, 131-144. [CrossRef]

67. Dickinson, D.; Villeval, M.-C. Does monitoring decrease work effort?: The complementarity between agency and crowding-out theories. Games Econ. Behav. 2008, 63, 56-76. [CrossRef]

68. Falk, A.; Kosfeld, M. The Hidden Costs of Control. Am. Econ. Rev. 2006, 96, 1611-1630. [CrossRef]

69. Schnedler, W.; Vadovic, R. Legitimacy of Control. J. Econ. Manag. Strategy 2011, 20, 985-1009. [CrossRef]

70. Barkma, H.G. Do Top Managers Work Harder When They Are Monitored? Kyklos 1995, 48, 19-42. [CrossRef]

71. Enzle, M.E.; Anderson, S.C. Surveillant intentions and intrinsic motivation. J. Pers. Soc. Psychol. 1993, 64, 257-266. [CrossRef]

72. Herzberg, F. One More Time: How do You Motivate Employees? The Harvard Business Review Classics Series; Harvard Business Press: Boston, MA, USA, 2008; ISBN 978-1-4221-2599-1.

73. Plant, R.W.; Ryan, R.M. Intrinsic motivation and the effects of self-consciousness, self-awareness, and ego-involvement: An investigation of internally controlling styles. J. Personal. 1985, 53, 435-449. [CrossRef]

74. Bulow, J.I.; Geanakoplos, J.D.; Klemperer, P.D. Multimarket Oligopoly: Strategic Substitutes and Complements. J. Polit. Econ. 1985, 93, 488-511. [CrossRef]

75. Chang, J.; Lai, C. Carrots or sticks? A social custom viewpoint on worker effort. Eur. J. Polit. Econ. 1999, 15, 297-310. [CrossRef] 
76. Becker, G.S. The Economic Approach to Human Behavior; University of Chicago Press: Chicago, IL, USA, 2008; ISBN 978-0-226-04112-4.

77. Frey, B.S. Economics as a Science of Human Behaviour: Towards a New Social Science Paradigm; Kluwer Academic Publishers: Boston, MA, USA, 1999; ISBN 978-0-7923-8434-2. 